\title{
Effect of electropulsing-ultrasonic surface treatment on the surface properties and the corrosion behavior of 45 steel-CORRIGENDUM
}

Bing Zhang, Haibo Wang, Shuo Zhang, Guolin Song, Song-Zhu Kure-Chu, Xinglong Wang, Jie Kuang, and Guoyi Tang

doi: 10.1557/jmr.2016.126, Published by Materials Research Society with Cambridge University Press, 16 May 2016.

In the original publication of this article, Figs. 6(a) and $6(\mathrm{~b})$ were missing a portion of the specimen figure. The corrected figure is shown below.

The authors regret this error.

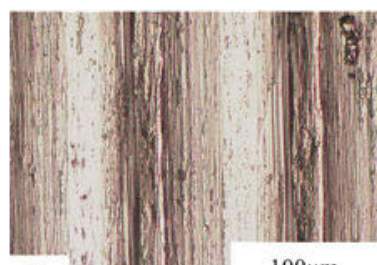

(a)
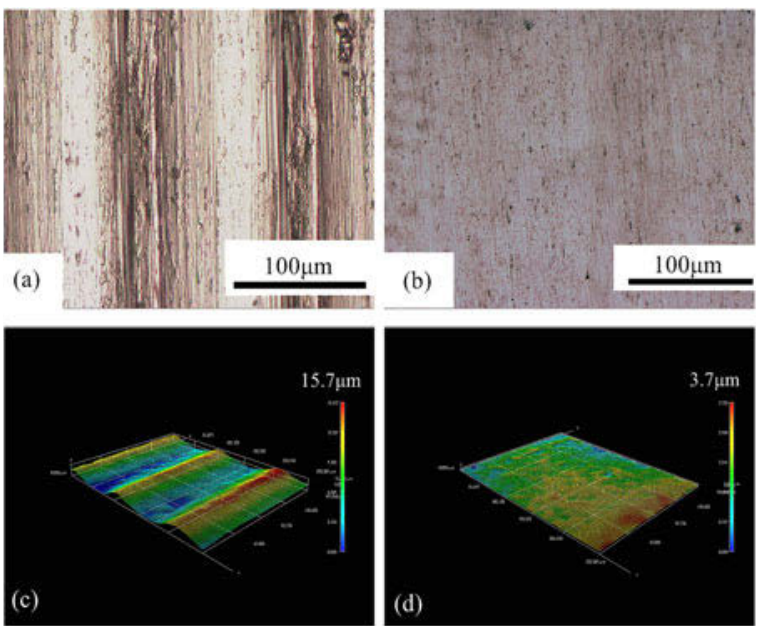

FIG. 6. The surface morphology of 45 steel specimens obtained by 3D digital microscope (a) optical surface image after turning, (c) threedimension surface morphology image after turning, (b) optical surface image treated by EUST, and (d) three-dimension surface morphology image treated by EUST.

\section{REFERENCE}

1. B. Zhang, H. Wang, S. Zhang, G. Song, S-Z. Kure-Chu, X. Wang, J. Kuang, and G. Tang: Effect of electropulsing-ultrasonic surface treatment on the surface properties and the corrosion behavior of 45 steel. J. Mater. Res. 31, 2114-2124 (2016). doi: 10.1557/ jmr.2016.126. 